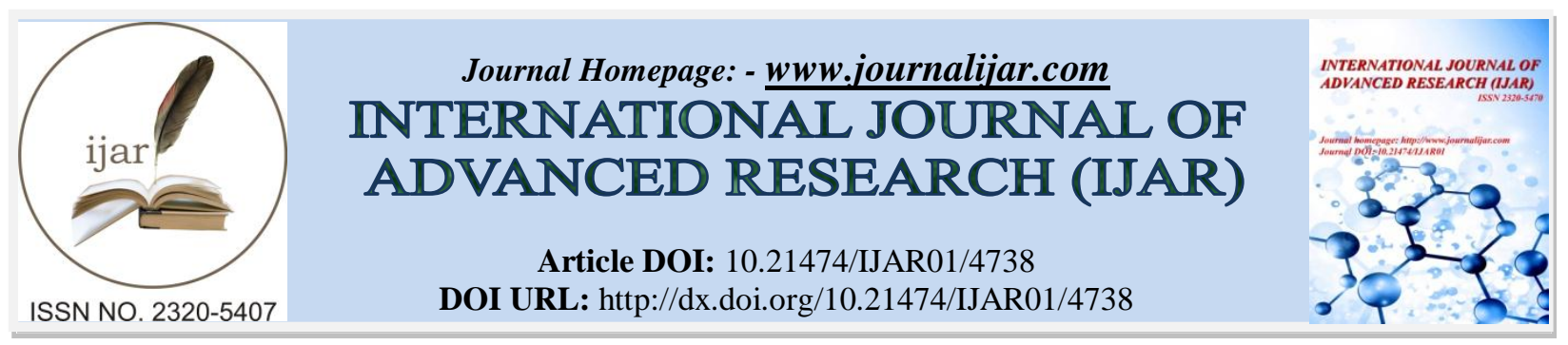

RESEARCH ARTICLE

\title{
FIVE PILLARS OF DEVELOPMENT AND SOCIAL DEVELOPMENT OF A PRESCHOOL CHILD: EARLY CHILDHOOD INTERVENTION.
}

1. Regional Institute of Education (NCERT), Bhubaneswar.

2. Maharaja Krushna Chandra Gajapati Medical College, Berhampur.

\section{Manuscript Info}

Manuscript History

Received: 4 May 2017

Final Accepted: 6 June 2017

Published: July 2017

\section{Abstract}

This study was designed to investigate the impact of five pillars of development on social development of a preschool child in order to determine if these five pillars of development i.e concrete preparation, cognitive challenge, meta cognitive orientation, social construction and bridging promote the development of social skills in preschool children. It was hypothesized that there was no relationship between the concrete preparation, cognitive challenge, social construction, meta cognition and bridging with the development of social skills of a preschool child. The central constructs were assessed through $\mathrm{ABAB}$ Design Experiment and the methods adopted for this purpose was intervention of activities and observation of the social skills in child. The sample consisted of only one child of 3 years of age. For the study, the child was assessed for social skills before the start of the course, after he completed the course, and at follow-up period. Results indicated that there is a relationship exists between the five pillars of development and the social development of the child. The study provides an empirical support for the theoretical link between the five pillars of development and the social development of children.

Copy Right, IJAR, 2017,. All rights reserved.

\section{Introduction:-}

Many researchers have found that a generational shift - a complex interaction of family structure changes, drastic revolutions in work patterns, a changing perception of the child's role in society and the family, and advancements in both birth control and fertility treatments - has resulted in an increased sense of pressure and responsibility on the parenting role that did not exist in prior generations (Senior, 2014). This might explain, then, the fascination with and popularity of current media depictions of parents being significantly unhappy when compared to nonparents (Nelson et al, 2013).

According to Baumrind $(1967,1971)$, there exist four types of parenting styles in the society and they are authoritarian, authoritative, permissive and uninvolved/neglectful which were found to be the important source of defining the behavior and attitude of parents toward their children (Joshi et al, 2009). Apart from this, cultural surroundings and home environment is associated with the interaction between parents and children (Keshavarz \&

Corresponding Author:-Dr. Jagatshreya Satapathy.

Address:-. Maharaja Krushna Chandra Gajapati Medical College, Berhampur. 
Baharudin, 2009). Culture influences many aspects of the family life and the ways adopted by the parents in socializing their children (Kagitcibasi, 1996).

According to Bandura's experiments on social modeling, one can encourage and modify the behaviors of children by making them observe role models engaging in those behaviors and therefore there is no need of rewards. He stated that the children are aware of the motives of adults and are motivated to imitate them because parents and family members become the role models for their children in one or the other way (Bandura, 1977). Parents today are under informed about the scientific findings about the best ways of parenting (Rankin, 2005) and hence take parenting advices from others and are oversaturated with them (Sclafani, 2004; Smith \& Pugh, 1996). Many researchers have already stated that children aggression and other behaviour problems of children are related with poor parenting practices (Brotman et al., 2009; Linville et al.,2010; DeKlyen et al., 1998; DeVito \& Hopkins, 2001). With this, abusive parenting and its negative influences, specifically, are well documented, and research says that there is a strong correlation between corporal punishment and negative consequences for children (Deater-Deckard et al., 1996; Gershoff \& Bitensky, 2007). Poor parenting practices leave a significant impact on school and community climates (McVittie \& Best, 2009).

Zone of proximal development as stated by Vygotsky can be defined as the distance between what the learner can do by his own and what he can do with the help of adults and more capable ones, this can be best determined through problem solving under one's guidance or with the co-operation of more capable peers. It enhances the level of one's potential. He added that parenting styles plays an eminent role for the cognitive and social development of children needed for further success in school. The term 'Scaffolding' given by him establish the fact that the development of children depends on the level of support and guidance of parents. Scaffolding is nothing but to provide appropriate assistance to the child till he/she gets enough of a boost in order to achieve the task. It helps the child to learn the task and master over it with the help of assistance provided by the more capable ones. With the help of scaffolding the child will be able to do the task again on his own without any assistance or help of others (Vygotsky, 1978).

\section{Rationale:-}

Robertson (2006) in his book named has established that there are five pillars which can help in better development of children both mentally and socially. They are concrete preparation, cognitive challenge, social construction, meta cognition and bridging. Concrete preparation is the stage where the parents are required to consolidate the outside walls of existing knowledge and bring it to the fore, ready for use. Appropriate opportunities are provided to the children to interact with the outside world in order to satisfy their thirst of knowing different things, adding to the existing stock of knowledge, to observe the existing phenomenon and facilitate them to create their own understanding. Cognitive challenge are the challenging activities those are provided by the mentors to the children in order to help them to complete these tasks in such a way that the children will remember and learn them in a long term basis and will be able to foster the same while meeting with the similar problems by their own from their past experiences. Social construction, the next pillar of development helps children to interact with the adults and the people around them without facing difficulties and understand the culture of society in which they lives in such a way that they will be adaptable to the existing environment by watching, listening, observing the activities and following each other, trying out different things and learning to survive in the environment together with other social beings. Fourth component is meta cognition which creates self awareness in children which further foster self esteem and self confidence in them. It can be carried out by making children aware of their own thinking, think of themselves as learners and all the activities they do in their lives. In this way they gradually learn to capture their thoughts as they occur and they come to know that they have their own ideas. Bridging can otherwise be called as transfer of learning which means the children will be capable of linking their one experience or learning with another in an appropriate way. It develops ability of applying prior knowledge and experience of one context with the similar other context. Addition to this, Robertson stated that the above first four components will be able to make children learn by discoveries. It not only helps them to understand the things but remember the things for a long term basis. It will also provide them with the ability of applying their learning to other situations. Therefore, bridging helps them in activating and building background knowledge, in facilitating predictions and to create interests and connections (Robertson, 2006). Fullest potential of children can be enhanced with the daily activities and interaction between the parents and the children. Studies are not found where it is given that the daily interaction of parents involving these five pillars of development with the children will be efficient to foster appropriate social entry skills in preschool children. So, finally the present study is an attempt to find out that whether the daily basis action of parents involving these five components while interacting with children will be able to enhance the social skills of children in an appropriate way. 


\section{Objective of the study:-}

(1) To examine the extent of development of social skills in child due to the five pillars of development.

\section{Hypothesis of the study:-}

$\mathbf{H}_{\mathbf{O}}$ :-

There is no relationship between the concrete preparation, cognitive challenge, social construction, meta cognition and bridging with the development of social skills of a preschool child.

\section{Procedural and Methodological Section:-}

Selection of the subjects or participants of the study:-

A 3year child was taken as a sample by the investigator and the research was undertaken by her for 2 years continuously without break. Impact of these five pillars was measured through observation of the activities and interaction of the child with the parents and the strangers.

\section{Decision about the instrument or methods of data collection:-}

Observation through video and audio recording was used for the assessment of the social skills before the intervention, during the intervention and after the intervention. The conversations were transcribed into English language by the investigator after the process of data collection.

\section{Research Design used in research study:-} About the design:-

A: Observation of the activities and interaction of the child with the strangers on the presence of his/her mother. This was conducted when activities were not introduced. It took 6 months of observation.

B: Observation conducted by the investigator in order to observe the interaction of the child with others during the intervention of the activity. It continued for another 6 months.

A: Investigator again observed the interaction of the child with others when the interventions were withdrawal. It continued for 6 months.

B: Again the investigator made the child to do some activities and then the child was observed by her for more 6 months when intervention was on.

For this purpose, a 3year child was taken as a sample by the investigator and the research was undertaken by her for 2 years continuously without break. Impact of these five pillars was measured through observation of the activities and interaction of the child with the parents and the strangers. Various activities were conducted to test the hypothesis but it was impossible to discuss all the activities undertaken during the investigation, therefore only one activity was discussed here.

\section{Activity:-}

The investigator used the photo album containing the photos of the child himself and the entire family of the child. Family photo album was used in order to grab his attention first.

\section{Concrete Preparation:-}

The investigator showed the photos to the child. The photos contained three generations. The name and age of the family members were read aloud by the investigator. Then the child was told by the investigator that these people belonged to the same family. Mother tongue was used by the investigator during the whole process. The child was asked to point out each and every person of his family to give some information about them.

\section{Aim of the activity:-}

To see if the child is using the vocabulary expected.

To find out if the child begins to understand relationships within his own family.

\section{Cognitive Challenge:-}

The child was asked to put the family in sequence or order. He was given freedom to choose any order (e.g. age, height, all adults of the family first and then all children). 


\title{
Aim of the activity:-
}

To see in what way he is ordering the people.

To make the child learn sequencing.

\section{Meta cognition:-}

Investigator shuffles the photos around the table and asked the child to put the photos in order again but in different way. During the process of the activity, the investigator encouraged the child to express his own idea verbally.

After the completion of the task, the investigator asked few questions like; what did you think about when you were doing this? how did you choose the order? what helped you to do this task?

\section{Aim of the activity:-}

To see how the child express his ideas verbally.

To make the child realize what and how is he completing the task.

\section{Social Construction:-}

The child was encouraged to come to the investigator comfortably without his mother and feel free to interact with others. He was free to do and talk anything with the investigator and others in the building.

\author{
Aim of the activity:- \\ To see how the child behaves with strangers on the absence of his parents. \\ To make the child comfortable while talking and putting his own ideas. \\ To make the child learn how to wait for his own turn to speak.
}

\section{Bridging:-}

In this activity, the child was asked few questions and it was literally a small discussion about the family. He was asked like if you were going to give chocolates to your family members in order, I wonder what order you would like to choose. The child was encouraged to put his own ideas verbally and comfortably. The investigator asked further questions like why? Who would go first in that order? What have we learnt that would help us the next time we want to put something in order? Why do we put things in order? What else do we put in order - either in class or at home?

\section{Aim of the activity:-}

To make the child understand the need of seriation.

\section{Procedure adopted for data collection:-}

$\mathrm{AB} A \mathrm{~B}$ design was used to introduce each activity as an intervention and 5days were used to observe the activity, social skills, practices, course of action, turn taking, syntax for conversation, the structure of speech events, and the integration of speech and gesture. In other words, the study focused on participants' contextualized perspectives and interpretations of behavior, events, and situations. Data collection strategies included the collection of videotapes, audiotapes, or both of talk-in-interaction, which were then transcribed according to the conventions. Videotapes were strongly preferred because of the importance of embodied aspects of interaction.

\section{Inferential and concluding section:- Data analysis techniques:-}

The kinds of data analyzed included naturally occurring data from either ordinary conversation (i.e., ordinary chatting among friends but are not limited to, the organization of sequences (i.e., courses of action), turn-taking and repair practices, syntax-for-conversation, the structure of speech events, and the integration of speech and gesture. The research should aim to uncover an emic perspective. In other words, the study focused on participants' contextualized perspectives and interpretations of behavior, events. The primary data in the study included the conversational and other behaviors that participant produce for each other in real time. The notion of context was principally understood as the talk that immediately precedes and follows the conversational object under study; this is sometimes referred to as the context of talk. Other important aspects of context included the integration of embodied action and gesture with talk. The study established theoretical links to other perspectives on talk-ininteraction, such as Vygotsky and analyses of learners' zones of proximal development. Data collection strategies included the collection of videotapes, audiotapes, or both of talk-in-interaction, which are then transcribed according to the conventions. In all cases, the recordings were considered to be the definitive source of information about the 
behaviors that were observed. Transcripts are understood as a tool for analysis to be used in conjunction with recordings.

\begin{abstract}
Analyses:-
In single-case research, evaluation of results primarily focuses on whether the change in the outcome variable is caused by the experimenter-controlled independent variable (intervention) and is reliable and not due to chance. In addition to this evaluation of experimental analysis, results should be evaluated on an applied criterion; examination of the importance and meaningfulness of the changes. In order to analyze the data from this study, only qualitative methods were used. Researcher transcribed audio and video recordings from the researcher-child activities on a computer. Identifying information was removed from the transcriptions. Once transcribed, researcher coded each transcription. The coding scheme had been extensively developed and revised. Parent-child interactions, stranger child interactions about the special event, and researcher-child interactions before, during and after the interventions all were coded differently.
\end{abstract}

\title{
Coding of Parent-Child Interaction:-
}

When coding for the parent-child interaction, researcher coded for the items by hand for the child dialogue: number of adjectives and adverbs, number of objects mentioned from the event object list, number of other objects that were not on the event object list, number of concepts mentioned from event concept list, and number of activities mentioned from the event activities list. Researcher also coded every sentence of the parent or caregiver dialogue. The number of adjectives and adverbs was coded for as well as the parent or caregiver's sentence structure. Parent or caregiver's sentences could be coded in many different ways. Sentences could be coded as memory questions, which is when a parent asks a child to provide a piece of information from memory about the event. The sentences could be coded as yes/no questions, meaning when the parent asks a child a question in which the child is only required to confirm or deny information provided by the parent. Sentences could be coded as context statements, which is when there is a statement that does not require a response such as 'wow' or 'okay.' Finally, they could also be coded as evaluations, which are when a parent confirms or denies the child's previous statement as correct or incorrect. Repeated memory questions and yes or no questions were also coded for. These repeated questions were questions that had previously been asked by the parent. Repeated context statements, statements that were contextually very similar or exactly the same as the previous statement were also accounted for. Researcher obtained the number of words and the total number for the interview of sentences via the computer for both the child and the parent in the conversation.

\section{Coding of Researcher-Child Interaction:-}

When coding the researcher-child interaction just the child portion of the interaction was coded since the researcher portion was a scripted interaction. For each individual question that the researcher asked, the researcher coded for the number of words, the number of adjectives and adverbs, the number of objects mentioned from the event object list, the number of other objects that were not on the event object list, the number of activities mentioned, the number of concepts mentioned, as well as the number of correct details mentioned, which is the number of objects and concepts listed by the child that were in the event. For all of the questions combined, the researcher coded for the total number of unique objects and total number of unique concepts. Unique objects and concepts are the total number of unique objects or concepts mentioned from the list when counting each object or concept only once. For example, if a child mentioned those whose hair are grey and look aged have been placed first and those whose hair seems black and look young have been placed later, for a unique concept, the coder only count the sequence of the family members were made on the basis of age only once. For all of the questions combined, the researcher also coded for the total number of words, the total number of adjectives and adverbs, the total number of objects mentioned from the event object list, the total number of other objects, the total number of concepts, and total number of correct details.

\section{Result:-}

Hypothesis of the study was there is no relationship between the concrete preparation, cognitive challenge, social construction, meta cognition and bridging with the development of social skills of a preschool child. From this study, it could be revealed that in one or the other way all the five pillars helped the child to interact without fear, understand the gestures and reactions of the people around, understand small instructions, how to compete without any personal enmity, how to take the things lightly and to do his things without help of elders etc. 


\section{Conclusion and interpretation:- Conclusion and Discussion:-}

Anne Robertson has introduced five pillars of cognitive development and the question was does these five pillars help in the development of social skills and social entry behaviours of preschool children and to what extent. How the parents can include these pillars in their day to day lives in order to develop social skills in their child. The investigator took five days to find it out and conducted some activities with the single child. First one is concrete preparation where the investigator showed the photos to the child. The photos contained three generations of the child's family members. The name and age of the family members were read aloud by the investigator in front of the sample child. Then the child was told by the investigator that these people belonged to the same family. The child was asked to point out each and every person of his family to give some information about them. It was found that the child was using the vocabulary expected and he was also able to understand relationships within his own family. According to Early Childhood consultant Sylvia Ford, it will help the children to know and understand the things, events or phenomenon on long term basis. It not only helps the children to learn and remember but also develop observation and imagination power. Second component is cognitive challenge where the child was asked to put the family in sequence or order. He was given freedom to choose any order (e.g. age, height, all adults of the family first and then all children). On the first trial the child choose to arrange the family according to their age and on the second trial, he arranged the family according to their height. The researcher could learn the way he was ordering the people and the activity made the child learn sequencing. Third one is meta cognition where investigator shuffled the photos around the table and asked the child to put the photos in order again but in different way. During the process of the activity, the investigator encouraged the child to express his own ideas verbally. After the completion of the task, the investigator asked few questions like; what did you think about when you were doing this? how did you choose the order? what helped you to do this task? It was found from the study the way the child was expressing his ideas verbally and this activity made the child realize what and how is he completing the task. One thing was noticeable that the child was confident enough while placing the photos in sequence. It might had been possible because he was taking interest in the activity and he knew the people very well. In order to make it clear, the investigator asked him to help her out while putting the family members (investigator's) in sequence. It was found that even though he didn't know the family members of the investigator, he was able to arrange them in sequence. Perhaps he could understand the ideas and intensions of the investigator even if it was not told to him before. Fourth one is Social Construction where the child was encouraged to come to the investigator comfortably without his mother and feel free to interact with others. He was free to do and talk anything with the investigator and others in the building. Researcher observed the way the child behaved with strangers on the absence of his parents and it was found that after the above three days of activities the child was comfortable while talking and putting his own ideas and the child learnt how to wait for his own turn to speak. Fifth one is Bridging where in this activity, the child was asked few questions and it was literally a small discussion about the family. He was asked like if you were going to give chocolates to your family members in order, I wonder what order you would like to choose. The child was encouraged to put his own ideas verbally and comfortably. The investigator asked further questions like why? Who would go first in that order? What have we learnt that would help us the next time we want to put something in order? Why do we put things in order? What else do we put in order - either in class or at home? From the above activities, it was found that the child understood the need of seriation. From the entire process, it was found that the child developed social skills like ways of dealing with others that create healthy and positive interactions. He could communicate clearly, calmly, and respectfully. He could share his ideas comfortably without fear. In one or the other way all the five pillars helped the child to interact without fear, understand the gestures and reactions of the people around, understand small instructions, how to compete without any personal enmity, how to take the things lightly and to do his own things without the help of elders etc.

\section{Bibliography:-}

1. Bandura, A. (1977). Social learning theory. Englewood Cliffs: NJ: Prentice Hall.

2. Baumrind, D. (1967). Child care practices anticeding three patterns of preschool behavior. Genetic Psychology Monographs , 43-88.

3. Baumrind, D. (1971). Current patterns of parental authority. Developmental Psychology Monograph , 4(1).

4. Baumrind, D. (1966). Effects of authoritative parental control on child behavior. Child Development , 887-907.

5. Baumrind, D. (1966). Effects of authoritative parental cotrol on child behaviour. Child Development , 887-907.

6. Baumrind, D., \& Black, A. (1967). Socialization practices associated with dimensions of competence in preschool boys and girls . Child Development, 291-328. 
7. Biblartz, T., Casper, L., \& Jayasundhara, R. (2009). Co-resident grandparents and their grandchildren: Family structure matters. Annual Meetings of the Population Association of America Paper Session 153. Generational Exchanges and the Well - Being of Grandchildren.

8. Brotman, L., O'Neal, C., Huang, K. -Y., Gouley, K., Rosenfelt, A., \& Shrout, P. (2009). An experimental test of parenting practices as a mediator of early childhood physical aggression. The Journal of Child Psychology and Psychiatry, 235-245.

9. Brown, A., \& Ferrara, R. (1985). Diagnozing zones of proximal development. In I. W. (Ed), Culture, communication and cognition: Vygotskian perspectives (pp. 273-305). Cambridge University: Press.

10. Cappa, K., Begle, A., Conger, J., Dumas, J., \& Conger, A. (2011). Bidirectional relationships between parenting stress and child coping competence: Findings from the PACE study. Journal of Child and Family Studies , 334342.

11. Cardoso, J., Padilla, Y., \& Sampson, M. (2010). Racial and ethnic variation in the predictors of maternal parenting stress. Journal of Social Service Research , 429-444.

12. Ceglowski, K. J. (2010). The impact of the relationship with the fatcher on adult children's self - esteem, attachment, and emotional expressivity. Masters Abstracts International .

13. Christogiorgos, S., \& Giannakopoulos, G. (2014). School refusal and the parent-child relationship:nA psychodynamic perspective. Journal of infant, Child, and Adoloscent Psychotherapy, 182-192.

14. Chu, C., Xie, Y., \& Yu, R. (2011). Coresidence with elderly parents: A comparative study of south east China and Taiwan. Journal of Marriage and Family, 120-135.

15. Copple, C., \& Bredekamp, S. (2009). Developmentally appropriate practice in early childhood programs. National Association for the Education of Young Children. Washington DC.

16. Deater-Deckard, K., Bates, J., Dodge, K., \& Pettit, G. (1996). Physical discipline among African American and European American Mothers: Links to children's externalizing behaviors. Developmental Psychology, 10651072 .

17. DeKlyen, M., Speltz, M., \& Greenberg, M. (1998). Fathering and early onset conduct problems: Positive and negative parenting, father-son attachment, and the marital context. Clinical Child and Family Psychology Review, 3-21.

18. DeVito, C., \& Hopkins, J. (2001). Attachment, parenting, and marital dissatisfaction as predictors of disruptive behavior in preschoolers. Development and Psychopathology, 215-231.

19. Erikson, E. (1982). The life cycle completed: A review. New York: Norton.

20. Fawcett, C., \& Markson, L. (2009). Similarity predicts liking in 3-year-old children. Journal of Experimental Child Psychology, 345-358.

21. Franco, L., Pottick, K., \& Huang, C. (2010). Early parenthod in a community context: Neighbourhood conditions, race-ethnicity, and parenting stress. Journal of Community Psychology, 574-590.

22. Gershoff, E., \& Bitensky, S. (2007). The case against corporal punishment for children: Converging evidence from social science research and international human rights law and implications for U.S. public policy. Psychology, Public Policy, and the Law, 231-272.

23. Grafenhain, M., Behne, T., Carpenter, M., \& Tomasello, M. (2009). One-year-old's understanding of nonverbal gestures directed to a third person. Cognitive Development , 23-33.

24. Kagitcibasi, C. (1996). Family and human development across cultures. Mahwah: NJ: Erlbaum.

25. Keshavarz, S., \& Baharuddin, R. (2009). Parenting style in a collectivist culture of Malaysia. European Journal of Social Sciences, 66-73.

26. Lecompte, V., \& Moss, E. (2014). Disorganized and controlling patterns of attachment, role reversal, and caregiving helplessness: Links to adolecent's externalizing problems. American Journal of Orthopsychiatry , 581-589.

27. Liem, J., Cavell, E., \& Lustig, K. (2010). The influence of authoritative parenting during adolescence on depressive symptoms in young adulthood: Examining the mediating roles of self-development and peer support. The Journal of Genetic Psychology, 73-92.

28. Osborne, C., Berger, L., \& Magnuson, K. (2012). Family structure transitions and changes in maternal resources and well-being . Demography, 23-47.

29. Pezella, F. (2010). Mozilla Firefox. Retrieved from Proquest Dissertations and Theses database.

30. Piaget, J., \& Inhelder, J. (1969). The Psychology of the Child. New York: Basic Books.

31. Plotnik, R., \& Kouvoumdjian, H. (2010). Introduction to Psychology. Belmont: CA: Wadsworth Publishing.

32. Pong, S., \& Chen, P. (2010). Co-resident grandparents and grandchildren's academic performance in Taiwan. Journal of Comparative Family Studies, 111-129.

33. Rankin, J. (2005). Parenting experts: Their advice, the research, and getting it right. Westport: CT: Praeger. 
34. Razo. (2009). Parenting practices of Latina mothers and children's behavior outcomes. Masters Abstracts International .

35. Robertson, A. (2006). Let's Think! Early Years. Institute of Education, University of London: G.L Assessment.

36. Robertson, A. (2006). Let's Think! Early Years. Institute of Education, University of London: G.L Assessment.

37. Rodriguez, C. (2011). Association between independent reports of maternal parenting stress and children's internalizing symptomatology. Journal of Child and Family Studies , 631-639.

38. Rosenthal, M. (2006). Be A Parent, Not A Pushover. Nashville, Tennessee: Thomas Nelson, Inc.

39. Sclafani, J. (2004). The educated parent: Recent trends in raising children. Westport: CT: Praeger.

40. Silver, D. (2011). Using the 'Zone' Help Reach Every Learner . Kappa Delta Pi Record, 28-31.

41. Smith, C., \& Pugh, G. (1996). Learning to be a parent: A survey of group-based parenting programmes. (National Children's Bureau).London: UK: Family Policy Studies Centre.

42. Stack, D., Serbin, L., Enns, L., Ruttle, P., \& Barrieau, L. (2010). Parental effects on children's emotional development over time and accross generations. Infants \& Young Children, 52-69.

43. Tavakolizadeh, J., Tabari, J., \& Akbari, A. (2015). Academic self-efficacy: predictive role of attachment styles and meta-cognitive skills. Procedia-Social and Behavioral Sciences , 113-120.

44. Timler, G., Olswang, L., \& Coggins, T. (2005). Social communication interventions for preschoolders: Targetting peer interactions during peer group entry and cooperative play. Seminary Speech Language , 170180.

45. Timpano, K., Keough, M., Mahaffey, B., Schmidt, N., \& Abramowitz, J. (2010). Parenting and obessive compulsive symptoms: Implications of authoritarian parenting. Journal of Cogntive Psychotherapy: An International Quaterly , 151-164.

46. Urman, A. (2012). Mozilla Firefox. Retrieved from Proquest Dissertations and Theses database.

47. Vaish, A., Missana, M., \& Tomasello, M. (2011). Three-year-old children intervene in third-party moral transgressions. British Journal of Developmental Psychology , 124-130.

48. Vallotton, C. (2008). Signs of emotion: What can preverbal children "say" about internal states? Infant Mental Health Journal , 234-258.

49. Vygotsky, L. (1978). Mind in society: The development of higher psychological processes. Cambridge: MA: Harvard University Press.

50. Vygotsky, L. (1978). Mind in society: The development of higher psychological processes. Cambridge: MA: Harvard University Press.

51. Whitson, M., Martinez, A., Ayala, C., \& Kaufman, J. (2011). Predictors of parenting and infant outcomes for impoverished adolescent parents. Journal of Family Social Work , 284-297.

52. Willits, L. A. (2014). Parent-training for parents of preschool and school sge children with language deficits: A pilot study in enhancing children's vocabulary growth and parent's perceptions, strategies and knowledge. Masters Abstracts International .

53. Wood, D., \& Middleton, D. (1975). A study of assisted problem-solving. British Journal of Psychology .

54. Wood, D., Bruner, J., \& Ross, G. (1976). The role of tutoring in problem-solving. Journal of Child Psychology and Child Psychiatry , 89-100.

55. Linville, D., Chronister, K., Dishion, T., Tudahl, J., Miller, J., Shaw, D., et al. (2010). A Longitudinal Analysis of Parenting Practices, Couple Satisfaction, and Child Behavior Problemsj. Journal of Marital and Family Therapy, 244-255.

56. Lowe, K., \& Dotterer, A. (2013). Parental monitoring, parental warmth, and minority youth's 119 academic outcomes: Exploring the integrative model of parenting. Journal of Youth and Adolescence, 1413-1425.

57. McVittie, J., \& Best, A. (2009). The impact of Alderian-based parenting classes on self-reported parental behavior. The Journal of Individual Psychology, 264-285.

58. Meijssen, D., Wolf, M., Koldweijin, K., van Wawwenger, A., Kok, J., \& van Baar, A. (2010). Parenting stress in mothers after very preterm birth and the effect of the 35 infant behavioural assessment and intervention program. Child: Care, Health and Development, 195-202.

59. Mollborn, S., Fomby, P., \& Dennis, J. (2011). Who matters for children's early development? Race/Ethnicity and extended household structures in the United States. Child Indicators Research, 389-411.

60. Monserud, M., \& Elder, G. (2011). Household structure and children's educational attainment: A perspective on co-residence with grandparents. Journal of Marriage \& Family, 981-1001.

61. Mortensen, J. A. (2015). The perspective role of the care giving relationship in child care for infants and toddlers from high risk families. Dissertation Abstracts International .

62. Mowder, B. (2010). Parent Behavior Importance Questionnaire- Revised (PBIQ-R) and Parent Behavior Frequency-Revised (PBFQ-R). Manual . 
63. Mowder, B. (2005). Parent development theory: Understanding parents, parenting perceptions and parenting behaviors. Journal of Early Childhood and Infant Psychology, 45-64.

64. Mowder, B. (1993). Parent role development parent role research. In B. Mowder, Early Childhood Interests.

65. Mowder, B. (2006). Parenting infants, toddlers, and young children: Contemporary research in relation to the parent development theory. Journal of Early Childhood and Infant Psychology, 79-98.

66. Mowder, B., \& Sanders, M. (2008). Parent behavior importance questionnaire and frequency questionnaires: Psychometric characteristics. Journal of Child and Family Studies , 675-688.

67. Mowder, B., \& Shamah, R. (2009). Parent assessment and intervention. In B.A Mowder, F. Rubinstein, \& A.E. Yasik, Evidence-based practice in infant and early childhood psychology. New York: Wiley.

68. Mowder, B., \& Shamah, R. (2011). Test-retestreliability of the parent behavior importance questionnairei revised and the parent behavior frequency questionnaire- revised. Psychology in the Schools , 843-854.

69. Mowder, B., Guttman, M., Rubinson, F., \& Sossin, K. (2006). Parenting and trauma: Parent's role perceptions and behaviors related to 9/11 tragedy. Journal of Child and Family Studies , 730-740.

70. Mowder, B., Harvey, V., Moy, L., \& Pedro, M. (1995). Parent role characteristics: Parent views and their implications for school psychologists. Psychology in the Schools , 27-37.

71. Mowder, B., Harvey, V., Pedro, M., Rossen, R., \& Moy, L. (1993). Parent role questionnaire: psychometric qualities. Psychology in the Schools, 205-211.

72. Mowder, B., Winderstrom, A., \& Sandall, S. (1997). Family dynamics. Infant development and risk, 125-154.

73. Mulder, \& Christian, E. (2014). The role of parental involvement in the social development of children with autism spectrum disorders. Dissertation Abstracts International .

74. Norizan, A., \& Shamsuddin, K. (2010). Predictors of parenting stress among Malaysian mothers of children with Down Syndrome. Journal of Intellectual Disability Research, 992-1003.

75. Novak, C. (2009). Mozilla Firefox. Retrieved from www.pqdtopen.proquest.com.

76. Novak, C. (2009). Mozilla Firefox. Retrieved from www.pqdtopen.proquest.com.

77. O'Doherty, K., Troseth, G., Shimpi, P., Goldenberg, E., Akhtar, N., \& Saylor, M. (2011). Third-party social interaction and world learning from video. Child Development, 902-915.

78. Ofahengaue - Vakalahi, H. (2011). Tongan grandparents and grandchildren: The impact of grandparenting. International Social Work, 580-598. 